\title{
CONSTRUCTION AND VALIDATION OF INTERNSHIP PROGRAMME INTEREST INVENTORY
}

\author{
1D.SAHEELA SHANTHA KUMARI , ${ }^{2}$ Dr. R. BABU
}

${ }^{1}$ Ph.D., RESEARCH SCHOLAR, ${ }^{2}$ PROFESSOR AND HEAD , DEPARTMENT OF EDUCATION, ANNAMALAI UNIVERSTIY, ANNAMALAI NAGAR, CUDDALORE DISTRICT, TAMIL NADU, INDIA

\begin{abstract}
:
The internship training programme is one of the most important elements of teacher education programme. It is an exercise designed to expose the student-teachers to the practical aspect of teaching profession and to enable them put into practice the theoretical knowledge acquired during classroom interactions with their instructors. The entire purpose of teaching is to make positive change in students. A teacher is presumed to be at his or her best if he or she is able to impart knowledge acquired over the years to produce positive change in the behavior of the learners. However, for a teacher to teach meaningfully, demands so much of his or her attention is an essential element in the teaching-learning process. The skill of teaching is inherent in individuals which needs to be developed through training and practice. So the investigator has made an attempt to construct and validate an inventory for the interest in internship training programme. According to the systematic validation procedure, the framed 30 items were finalized to 24 items constituting the internship training programme interest as a tool.
\end{abstract}

Key words: Interest, Internship and Teacher Educator.

Article Received: 18 October 2020, Revised: 3 November 2020, Accepted: 24 December 2020

\section{Introduction}

Education is the dynamic process of the life of every individual influencing his/her physical, mental, emotional, social and ethical development. The term education may be interpreted as the process through which experience or information is gained or it is used to indicate the result of such training of the product of the learning process. The aim of education is not only to develop individuals but also to make them as adjusting members of the society and useful citizens. Keeping these facts in mind different academic institutions and schools are set up in a community to provide experience, knowledge, skill and attitude for all round development of an individual.

School internship programme is a situation where a student-teacher is given the opportunity to try the act of teaching before actually getting into the real world of the teaching profession. The classroom grants student-teachers experience in the actual teaching and learning environment. It is an important course undergone by the students who are about to enter the teaching profession where they are expected to exhibit the theoretical skills obtained during the course in the institution into practical situation in real time.

The success of any educational reform depends upon the quality of teachers and in turn the quality of teachers depends to a large extent on the quality of teacher education and quality of teacher education mainly depends upon the teacher training institutions. Education is a nation building activity and teachers are the pillars of the educational system. The role of teacher and education in the reconstruction of society need no fresh emphasis. The trio, the teacher, the educational system and the society have seldom come to terms about their respective deal both independent and mutual. Now here, have the expectations been of a deeper and wider nature than in the case of an educator. Again, nowhere have they been so little explicit and undefined as in the case of teachers. Training colleges have conceived of or imagined a certain perspective in the functioning and behavior of the teacher in a school. Teacher is building future citizens of the country.

\section{Objective}


To construct and validate a new tool namely, Internship Programme Interest to measure the interest of teacher educator.

\subsection{Sample}

Simple random sampling technique has been used in the process of data collection for the sample of 100 teacher-educators working in the education colleges situated in Kanyakumari district.

\section{METHOD OF THE STUDY}

Normative survey method has been used in the present study.

\subsection{TOOL}

Interest of students play a pivotal role in selecting and studying suitable courses. One of the objectives of the present investigation is to study the teacher educator's internship programme interest and also to study if there is any significant difference between the selected pairs of sub-samples in their internship training programme interest. In order to realize the aforesaid objectives, the investigator constructed and validated the internship programme interest inventory. The details are given in succeeding paragraphs.

As there is no suitable tool available to measure the Internship Programme Interest of the teacher educators, the investigator decided to construct and validate a one. The investigator constructed internship training programme interest inventory which contains 30 items. In this inventory, for each item, three activities are given against A, B, $\mathrm{C}$ and the respondents are required to circle round the alphabet (A or B or C), which stands for the activity they liked most. Thus each item in the inventory is of a forced triad type. Out of these three activities under each item, only one clearly pertains to show interest in internship training programme. If that activity is preferred, a score of ' 1 ' is given as the preference reveals interest of the sample in internship training programme and if some other activity is preferred, a score of ' 0 ' is given as the preference shows lack of interest on the part of internship training programme.

Internship programme interest inventory intended for the pilot study has been administered with the sample of 100 teacher educators working in the education colleges situated in the Kanyakumari District of TamilNadu, India.

When the items are given a score of ' 1 ' if correct and ' 0 ' if incorrect, the assumption of normality in the distribution of right - wrong responses is unwarranted. In such cases the point biserial ' $r$ ' rather than biserial ' $r$ ' is appropriate. Point biserial ' $r$ ' assumes that the variable which has been classified into two categories can be thought of as concentrated at two distinct points along a graduated inventory or continuum.

The formula for the point biserial ' $r$ ' is

$$
\text { rpbis }=\frac{M p-M q}{\sigma} \times \sqrt{P Q}
$$

in which,

Mp and Mq are means of the two categories

$\mathrm{P}$ is the proportion of the sample in the first group

$\mathrm{Q}$ is the proportion of the sample in the second group

$\sigma$ is the SD of entire sample.

The analyses of the performance of all the 100 teacher educators in the study have been done. Out of 30 items used in the study, 6 items having the point bi-serial ' $r$ ' value less than 0.2 are found to be negligibly important and therefore discarded; the remaining 24 items which have the point bi-serial ' $r$ ' value greater than 0.2 are selected and chosen for final form of the study (Vide; Table -1). 
TABLE - 1

r - Value of internship programme interest inventory

\begin{tabular}{|c|c|c|}
\hline S. No. & r - value & $\begin{array}{c}\text { Selected / Not } \\
\text { Selected }\end{array}$ \\
\hline 1 & 0.381 & Selected \\
\hline 2 & 0.095 & Not Selected \\
\hline 3 & 0.041 & Not Selected \\
\hline 4 & 0.359 & Selected \\
\hline 5 & 0.364 & Selected \\
\hline 6 & 0.388 & Selected \\
\hline 7 & 0.197 & Not Selected \\
\hline 8 & 0.305 & Selected \\
\hline 9 & 0.408 & Selected \\
\hline 10 & 0.440 & Selected \\
\hline 11 & 0.457 & Selected \\
\hline 12 & 0.468 & Selected \\
\hline 13 & 0.414 & Selected \\
\hline 14 & 0.387 & Selected \\
\hline 15 & 0.383 & Selected \\
\hline 16 & 0.161 & Not Selected \\
\hline 17 & 0.347 & Selected \\
\hline & & \\
\hline
\end{tabular}

\begin{tabular}{|c|c|c|}
\hline S. No. & r - value & $\begin{array}{c}\text { Selected / Not } \\
\text { Selected }\end{array}$ \\
\hline 18 & 0.160 & Not Selected \\
\hline 19 & 0.390 & Selected \\
\hline 20 & 0.263 & Selected \\
\hline 21 & 0.428 & Selected \\
\hline 22 & 0.046 & Not Selected \\
\hline 23 & 0.537 & Selected \\
\hline 24 & 0.539 & Selected \\
\hline 25 & 0.523 & Selected \\
\hline 26 & 0.373 & Selected \\
\hline 27 & 0.435 & Selected \\
\hline 28 & 0.272 & Selected \\
\hline 29 & 0.320 & Selected \\
\hline 30 & 0.420 & Selected \\
\hline
\end{tabular}

An individual score is the sum of all scores of the 24 items. The score ranges from 0 to 24 . Thus, the maximum score that one can get in this scale is 24.

\begin{tabular}{|c|c|}
\hline SCORE & LEVEL \\
\hline Upto 17 & $\begin{array}{c}\text { Low Level Of } \\
\text { Interest }\end{array}$ \\
\hline Above 17 Upto & $\begin{array}{c}\text { Average Level Of } \\
\text { Interest }\end{array}$ \\
\hline Above 21 & $\begin{array}{c}\text { High Level Of } \\
\text { Interest }\end{array}$ \\
\hline
\end{tabular}

The developed tool namely internship programme interest inventory contains 24 multiple choice items for 24 marks.

3.2 Validity and Reliability of Internship Programme Interest Inventory The next step in the construction and validation of internship training programme Interest inventory is to find out, its reliability and the validity. The investigator consulted 10 Teacher Educators in Education Colleges, 5 Professors from Universities and 5 Academic Subject Experts to ascertain the content and face validity of the tool and necessary modifications were made based on their feedback. 
Internship Programme Interest Inventory has construct validity as the items are selected following rigid item analysis procedure described above. Its intrinsic validity was found to be 0.95 . The reliability of the test was found by test-retest method is found to be 0.91 .

\subsection{Norms for Internship Programme Interest Inventory}

Norms have been worked out for Internship Programme Interest Inventory for teacher educators. Percentile norms of entire sample were computed for Internship Training Programme Interest Inventory. They are given in Table -2 .

TABLE - 2

\section{Percentile norms of internship programme interest inventory for entire sample}

\begin{tabular}{|c|c|}
\hline PERCENTILES & ENTIRE SAMPLE \\
\hline $\mathrm{P}_{90}$ & 24.00 \\
\hline $\mathrm{P}_{80}$ & 22.00 \\
\hline $\mathrm{P}_{70}$ & 21.00 \\
\hline $\mathrm{P}_{60}$ & 20.00 \\
\hline $\mathrm{P}_{50}$ & 19.00 \\
\hline $\mathrm{P}_{40}$ & 18.00 \\
\hline $\mathrm{P}_{30}$ & 18.00 \\
\hline $\mathrm{P}_{20}$ & 16.20 \\
\hline $\mathrm{P}_{10}$ & 15.00 \\
\hline
\end{tabular}

The raw scores of Internship Programme Interest Inventory were converted into ' $Z$ ' scores and the ' $t$ ' scores for entire sample and are given in Table -3 .

TABLE - 3
' $Z$ ' and ' $T$ ' scores of internship programme interest inventory of entire sample

\begin{tabular}{|c|c|c|}
\hline RAW & $\mathbf{Z}$ & $\mathbf{T}$ \\
SCORES & SCORES & SCORES \\
\hline 12 & -2.32248 & -6.98778 \\
\hline 13 & -1.99674 & -6.88168 \\
\hline 14 & -1.67101 & -6.77557 \\
\hline 15 & -1.34528 & -6.66947 \\
\hline 16 & -1.01954 & -6.56337 \\
\hline 17 & -0.69381 & -6.45727 \\
\hline 18 & -0.36808 & -6.35117 \\
\hline 19 & -0.04235 & -6.24506 \\
\hline 20 & 0.283388 & -6.13896 \\
\hline 21 & 0.609121 & -6.03286 \\
\hline 22 & 0.934853 & -5.92676 \\
\hline 23 & 1.260586 & -5.82066 \\
\hline 24 & 1.586319 & -5.71455 \\
\hline
\end{tabular}

\section{CONCLUSION}

The tool namely Internship Programme Interest Inventory was constructed and validated as per the procedures. Further it will be highly used to measure the interest in internship of Teacher Educators of colleges of Education.

\section{REFERENCES}

Edward L Allen., (1957), "Techniques of attitude scale construction", Appleton-century Crafts, Inc., New york.

Best, John.w., and James Khan, V., (1999), "Research in Education", Seventh edition, Prentice Hall of India (Pvt) Ltd, New Delhi, India.

Garrett, H.E., (2017), "Statistics in psychology and education", Surjeeth Publications, New Delhi, India. 